\title{
Effectiveness of Acceptance and Commitment Therapy in Reducing Symptoms of Anxiety, Depression, and Suicidal Ideation in Iranian Veterans Referred to a Military Psychiatric Hospital
}

Haleh Shahed Hagh Ghadam

Islamic Azad University Varamin-Pishva Branch https://orcid.org/0000-0001-9845-7989

Amir Mohsen Rahnejat ( $\sim$ arahnedjat@yahoo.com )

https://orcid.org/0000-0002-2194-4698

Arsia Taghva

Aja University of Medical Sciences

Mohammad Reza Ebrahimi

Aja University of Medical Sciences

Vahid Donyavi

Aja University of Medical Sciences

Mohammad Reza Ghasemzadeh

Aja University of Medical Sciences

\section{Research}

Keywords: Acceptance and Commitment Therapy (ACT), anxiety, depression, suicidal ideation, veterans

Posted Date: August 12th, 2020

DOI: https://doi.org/10.21203/rs.3.rs-54602/v1

License: (c) (i) This work is licensed under a Creative Commons Attribution 4.0 International License.

Read Full License 


\section{Effectiveness of Acceptance and Commitment Therapy in Reducing Symptoms of Anxiety, Depression, and Suicidal Ideation in Iranian Veterans Referred to a Military Psychiatric Hospital}

1. Haleh Shahed hagh ghadam

M.Sc in Clinical Psychology

Email: haleh.shahed@gmail.com

2. Amir Mohsen Rahnejat* (Corresponding Author)

PhD, Assistant Professor, Department of Clinical Psychology, Aja University of Medical Sciences, Tehran, Iran

Email: arahnedjat@yahoo.com

Tel: 021- 22195164

Fax: 021- 22197198

3. Arsia Taghva

MD, Professor, Department of psychiatry, Aja University of Medical Sciences, Tehran, Iran

Email: ataghva@yahoo.com

4. Mohammad Reza Ebrahimi

MD, Assistant Professor, Department of psychiatry, Aja University of Medical Sciences, Tehran, Iran

Email: mohammadreza_ebrahimi25@yahoo.com 


\section{Vahid Donyavi}

MD, Associate Professor, Department of psychiatry, Aja University of Medical Sciences, Tehran, Iran

Email: donyavi_vahid@yahoo.com

6. Mohammad Reza Ghasemzadeh

MD, Assistant Professor, Department of psychiatry, Aja University of Medical Sciences, Tehran, Iran

Email:m.rezaghasemzadeh@yahoo.com 
Background: Veterans are more exposed to mental disorders, especially anxiety, depression, suicidal ideation, and suicide attempt, due to the important role they played in defending their country. This study aimed to investigate the effect of Acceptance and Commitment Therapy (ACT) on reducing anxiety symptoms, depression symptoms, and suicidal ideation.

Methods: This study was conducted following a pretest-posttest quasi-experimental study design in 2020. The study included two groups, the experimental group and the control group awaiting treatment. The participants in this study consisted of 20 veterans who were selected using availability sampling and randomly assigned to two groups, the experimental group and the control group awaiting treatment (10 in each group). The instruments used in this study included the Beck Anxiety Inventory (BAI-II), the Beck Depression Inventory (BDI-II), the Beck Scale for Suicidal Ideation (BSSI), and a researcher-made demographic information questionnaire. Participants in the experimental group received 12 sessions of Acceptance and Commitment Therapy (ACT) for two hours per week, and participants in the control group awaiting treatment did not receive any intervention and received only routine medications. The pre-test and post-test were administered to both groups. The data were analyzed by descriptive statistical indices and the univariate Analysis of Covariance (ANCOVA) using SPSS 22 software.

Results: The study results showed that Acceptance and Commitment Therapy (ACT) contributed substantially to managing and reducing anxiety symptoms, depression symptoms, and suicidal ideation in veterans in the experimental group. After the intervention, the mean scores of the experimental group on the variables of anxiety, depression, and suicidal ideation decreased as compared to the control group awaiting treatment, and these differences were statistically significant $(\mathrm{P}<0.001)$.

Conclusions: The results of this study revealed that Acceptance and Commitment Therapy (ACT) was effective in reducing the symptoms of anxiety, depression, and suicidal ideation in veterans.

Keywords: Acceptance and Commitment Therapy (ACT), anxiety, depression, suicidal ideation, veterans. 


\section{Background}

Mental disorders such as depression and anxiety are among the most important causes of suicide (1). Annually, one in four adults develops these disorders, and factors causing disability in the United States and Canada have been found in the groups aged 15-44 years (2). Relevant research shows that $90 \%$ of suicides are associated with mental disorders, among which depressive and anxiety disorders account for $60 \%$ of suicides (3). According to the statistics provided by the World Health Organization (WHO), 400 million people worldwide suffer from anxiety, and this phenomenon is the primary cause of 6 to 25 percent of all mental problems. Depression is also one of the most common mental disorders in the world (4). More than half of suicide victims had reported a depressive disorder before they died (5). Depression can lead to suicidal ideation (6), and reduction in depression is accompanied by a reduction in suicidal ideation (7). In suicidal ideation, the individual has thoughts or fantasies about committing suicide or self-harm, which are expressed verbally or in written form, and the individual has not yet taken any action in this regard (8). Suicidal ideation is associated with poor psychosocial functioning, future depressive disorders, dropout, high-risk sexual behaviors, aggressive behaviors, and substance abuse disorders (9).

On the other hand, war is one of the factors influencing the increase in the prevalence rate, time of onset, and course of some mental disorders among the soldiers who took part in war. The soldiers who took part in war or veterans suffer from more severe mental problems than the public. Some research suggests that in almost every four soldiers who return from war, one soldier suffers from severe mental problems such as post-traumatic stress disorder (PTSD), depression and anxiety spectrum disorders, aggression, suicidal ideation and suicide attempts, severe family and marital conflicts, etc., and mental complications caused by war may sometimes also last for years after war (10). Regarding the impact of war on the development of mental disorders, especially after the First and Second World Wars, Vietnam-Korea war, Arab-Israel war, Iran-Iraq war, and the Persian Gulf war, extensive research has been so far conducted on the soldiers and those who took part in wars in various countries, indicating the devastating impacts of war and presence on the battlefield on individuals' behavioral responses and mental states $(11,12)$. Nearly $20 \%$ of deaths caused by suicide in the United States have also occurred among veterans (11). Studies reveal that a large number of veterans in the United States have reported mental health problems, of whom 19.5$22.8 \%$ had traumatic brain injury (TBI) and 24.4\% reported having PTSD (Institute of Medicine, 2014) (12, 13). Moreover, in 2014 in the United States, female veterans (46.5\%) had reported a higher prevalence of major depressive disorder (MDD) during their lifetime compared to male veterans (36.3\%) (14). According to reports in 2014, only $30 \%$ of the total population of veterans

in the U.S. health care system sought mental health care (15). From 1999 to 2014, the suicide rate for female and male veterans increased by 62.4 and 29.7 percent, respectively (16). Depressive disorder is known as a risk factor for suicide, as frequently reported in many studies $(17,18,19$, 
20, 21, 22, 23). In the U.S. veteran community, the generalized anxiety disorder was between 5 and 20 percent $(24,25,26)$.

Due to the high prevalence of mental disorders, especially depression, anxiety, and suicidal ideation among veterans, addressing therapeutic interventions in this group is of particular necessity. One of the interventions with approved effectiveness in recent years is Acceptance and Commitment Therapy (ACT), one of the third wave therapies utilizing for depression, anxiety, and suicidal ideation. ACT is based on encouraging the individuals seeking treatment to accept unpleasant feelings instead of attempting to control or change them. It also applies full awareness strategies empirically investigated and is regarded as an indicator of the behavioral school. This approach is based on full awareness, which is the complete acceptance of the current experience and dropping barriers consciously (27). Using processes such as increased acceptance of experience and mindfulness, ACT aims at treating inefficient and problematic escape from psychological pain (such as suicidal ideation and suicide attempt) (28).

In this approach, acceptance is not just tolerance, but the non-judgmental acceptance of experience in the present. The goal of treatment is to make it more possible to gain psychological flexibility. In addition to acceptance, having a sense of commitment to action is essential as well. Commitment is to make informed decisions about what is important in life and what one likes to do to manage a valuable and meaningful life. Objective assignments and behavioral exercises were utilized in the ACT as a way to build effective patterns of action that help treatment seekers follow their values (29). ACT increases psychological flexibility associated strongly with mental health (30). Various studies have shown the effectiveness of ACT in reducing depression in patients with chronic pain (31), improving the quality of life of veterans (32), and reducing depression in soldiers (33). Furthermore, a study suggests that experiential acceptance and mindfulness, which are pillars of ACT, have significantly improved veterans' anxiety and depression (34). Anxiety, depression, and suicidal ideation, each alone, are the debilitating disorders among veterans, and no doubt identifying the most effective ways is of great importance. Therefore, due to the necessity and importance of the subject, the present study aimed to provide an effective short-term treatment model to reduce the symptoms of anxiety and depression disorders as well as suicidal ideation among Iranian veterans in 2020.

\section{Methods}

Given the main purpose of this study, which was to determine the effectiveness of AcceptanceCommitment Therapy (ACT) in reducing anxiety symptoms, depression symptoms, and suicidal ideation in veterans, it employed a two-group pretest-posttest quasi-experimental study design based on random selection. Both groups were observed or measured twice. The first observation was performed by administering a pre-test to both the experimental group and the control group

awaiting treatment using the Beck Depression Inventory (BDI-II), Beck Anxiety Inventory (BAIII), the Beck Scale for Suicidal Ideation (BSSI), and a researcher-made demographic information questionnaire. Immediately upon completion of the treatment intervention, the second observation 
was performed by administering a post-test to both the experimental group and the control group awaiting treatment using the instruments used in the pre-test phase. In this plan, the first experimental treatment, i.e. ACT, was administered to the first group in 12 two-hour treatment sessions over 12 weeks according to the relevant protocol, and the second group (the control group awaiting treatment) did not receive any intervention and only received relevant pre- and post-tests and routine medications. It should be pointed out that both groups took drugs.

The current study population included veterans referred to one of Iran's military psychiatric hospitals in 2020. Using the availability (convenience) sampling and a formula for estimating the sample size, $\boldsymbol{n}=\frac{\left(\sigma_{1}^{2}+\sigma_{2}^{2}\right)\left(Z_{\frac{\alpha}{2}}+Z_{\beta}\right)^{2}}{\left(\mu_{1}-\mu_{2}\right)^{2}}$, the sample size was calculated to be 10 in each group, and by considering 2 groups, in total, 20 samples were included in this study. At this stage, the participants who met the inclusion criteria were randomly assigned to the experimental group and the control group awaiting treatment.

Inclusion criteria included employed or retired veterans with a history of taking part in war zones in the 8-year Iran-Iraq war; having diagnostic criteria for depression, anxiety, and suicidal ideation diagnosed by a psychiatrist and a clinical psychologist; undertaking structured clinical interviews; failure to receive psychological therapies at least one month before entering the study; having at least a high-school diploma; early diagnosis of depression, anxiety, and suicidal ideation, if any concomitant disorders exist; and conscious desire and willingness to participate in research. Exclusion criteria included taking psychotropic or narcotic drugs to reduce the symptoms of anxiety and depression, non-adherence to assignments, unwillingness to participate in the research and continue attending intervention sessions, and education level less than a high-school diploma.

It should be pointed out that this research was approved by the Vice-Chancellor for Research and Technology of the Medical University for the Islamic Republic of Iran's Army (AJA University of Medical Sciences) (code of ethics: IR.AJAUMS.REC.1399.010). The most important ethical issues observed were respecting the participants' right to choose to participate in the study, the confidentiality of personal information, providing the necessary information on how to implement the research project, and providing therapeutic interventions to the control group after the end of the study. Also, at the end of the study, the control group awaiting treatment underwent therapeutic intervention in terms of adherence to ethical considerations.

In this study, the following instruments were used to collect data:

1. Beck Anxiety Inventory (BAI-II): It is a self-report questionnaire designed to measure the severity of anxiety in adolescents and adults. This inventory is a 21-item scale in which the subject selects one of four options in each item indicating the severity of anxiety. Each BAI item is rated on a 4-point scale ranging from 0 to 3 , with a maximum score of 63 indicating clinical severity of anxiety. The cut-off points suggested for this inventory are shown in Table 1. This inventory has high validity. Its alpha coefficient, as a measure of internal consistency, is 0.92 , its test-retest 
reliability coefficient for a one-week interval is 0.75 , and the correlation of its items varies from 0.30 to 0.76 . Each test item describes one of the most common symptoms of anxiety (mental symptoms, physical symptoms, and panic). Therefore, the total score on this inventory ranges from 0 to $63(35,36)$.

Table 1: Determining the degree of anxiety based on the Beck Anxiety Inventory (BAI-II)

\begin{tabular}{|l|l|}
\hline Degree of anxiety & Scores \\
\hline No or minimal & $0-07$ \\
\hline Mild & $8-15$ \\
\hline Moderate & $16-25$ \\
\hline Severe & $26-63$ \\
\hline
\end{tabular}

2. Beck Depression Inventory (BDI-II): This inventory is a self-report tool developed to measure the severity of depression in people aged 13 to 80 years. This questionnaire consists of 21 items designed to assess the symptoms of depression (such as sadness, sense of failure, feelings of guilt, etc.). In BDI-II, items are rated on a 4-point Likert scale ranging from 0 to 3 . The total score of BDI-II varies from 0 to 63 . Scores between 5 and 9 indicate no depression or minimal depression, scores between 10 and 18 indicate mild depression, scores between 19 and 29 indicate moderate depression and scores between 30 and 63 indicate severe depression. The inventory has been widely used for research as well as clinical purposes, and its psychometric properties have been well established. Beck, Steer, and Brown reported an internal consistency of 0.73 to 0.92 with an average of 0.86 and an alpha coefficient of 0.86 for the patient group and 0.81 for the non-patient group $(37,38)$.

3. Beck Scale for Suicidal Ideation (BSSI): It is a 19-item self-assessment tool designed to disclose suicidal attitudes, behaviors, and plans and measure their severity. BSSI is a combination of three factors: the tendency to die (5 questions), preparedness for committing suicide (7 questions), and actual suicidal tendency (4 questions). Two questions dealing with deterrents to suicide or concealment of suicide have not been considered in any of the above three factors. This inventory has high reliability. Cronbach's alpha coefficients have ranged from 0.87 to 0.97 and the test-retest reliability coefficient has been obtained at 0.54 (39).

4. Researcher-made demographic information questionnaire: This questionnaire consisted of questions designed to collect information about age, marital status, number of children, level of education, employment status, length of stay on the battlefield, total percentage of veterans' sacrificing in their medical records, history of hospitalization, and taking psychiatric medications at the time of the research. 
5. Structured Clinical Interview for DSM-IV Axis I Disorders (SCID-DSM-IV-TR): This tool is performed by a clinical trainer or a trained mental health expert familiar with the diagnostic criteria and classification of disorders in DSM-5. The population interviewed includes psychiatric patients or patients with general medical diseases. The diagnostic coverage and the language used in SCID-5 make it suitable for people over 18 years of age; however, with a small change in the wording of questions, it may be possible to apply it to adolescents as well. A normal person is capable of understanding the SCID-5 language. Conducting SCID interviews with individuals with severe cognitive impairment, restlessness, or severe psychotic symptoms may be impossible. These individuals are often identified in the first ten minutes when performing the general examination. In such cases, the SCID can be applied as a diagnostic checklist for conducting interview with other informed sources.

6. ACT protocol: It was developed by Robyn Walser et al. in 2012 to treat anxiety and depression spectrum disorders as well as suicidal ideation in veterans. It is performed in approximately 12-16 individual psychotherapy sessions. The protocol includes specific information such as 1 - theory and background of behavior (for example, the role of language in human suffering), 2implementing six main treatment processes, 3- concentrating on the patient's specific skills (for instance, mindfulness), 4- building up a therapeutic alliance, 5-assigning tasks to the patient, and 6- useful appendices (for example, sheets containing internet information and telephone line if necessary) $(40,41)$.

According to Table 2, the content of each session, which is based on the ACT treatment protocol for depression, anxiety, and suicidal ideation, is provided as follows.

Table 2: How to implement the ACT protocol

The data obtained in this study were analyzed by descriptive statistical indices such as frequency, percentage, mean, and standard deviation and the univariate Analysis of Covariance (ANCOVA) using SPSS software version 22.

\section{Results}

In the present study, 20 veterans referred to a military psychiatric hospital were examined. They were assigned into two groups of 10, 10 in the experimental group and 10 in the control group awaiting treatment. In terms of marital status, $80 \%$ were married and $20 \%$ were single in the experimental group, and in the control group awaiting treatment, $90 \%$ were married and $10 \%$ were single. In terms of the level of education, $70 \%$ of the subjects in the experimental group had a high-school diploma, $10 \%$ an associate's degree, and 20\% a bachelor's degree, and in the control group awaiting treatment, $90 \%$ had a high-school diploma, and 10\% had an associate's degree. In terms of the age range, the experimental group had a minimum of 28 and a maximum of 55 with an average age of 41.5 years, and the control group awaiting treatment had a minimum of 26 and a maximum of 54 with an average age of 40 years. 
The univariate Analysis of Covariance (ANCOVA) was used to evaluate the effect of ACT and whether it reduced the symptoms of anxiety, the symptoms of depression, and suicidal ideation in veterans. The results obtained from this analysis confirmed the effect of ACT on reducing the symptoms of anxiety in veterans. Therefore, it can be concluded that this treatment was effective (Tables 3-8).

Table 3: Mean and standard deviation of pre- and post-test scores on the symptoms of anxiety in study groups

\begin{tabular}{|c|c|c|c|c|}
\hline \multirow{3}{*}{ Study variables } & \multicolumn{4}{|c|}{ Study groups } \\
\hline & \multicolumn{2}{|c|}{ Experimental } & \multicolumn{2}{|c|}{ Control awaiting treatment } \\
\hline & Mean & $\begin{array}{l}\text { Standard deviation } \\
\text { (SD) }\end{array}$ & Mean & $\begin{array}{l}\text { Standard deviation } \\
\text { (SD) }\end{array}$ \\
\hline $\begin{array}{l}\text { Symptoms of anxiety } \\
\text { (Pre-test) }\end{array}$ & 10.30 & 21.5 & 70.30 & 66.4 \\
\hline $\begin{array}{l}\text { Symptoms of } \\
\text { Anxiety (Post-Test) }\end{array}$ & 30.21 & 20.5 & 27 & 44.5 \\
\hline
\end{tabular}

The mean and standard deviation of the participants' scores on the BAI-II in the pre-test and posttest stages in terms of the study group are shown in Table 3. As shown in the above table, in the experimental group, the participants' mean scores on the BAI-II in both stages were 10.30and30.21, respectively. While the mean scores of the participants in the control group awaiting treatment in both stages were 70.30 and27, respectively. Therefore, it can be concluded that ACT reduced the symptoms of anxiety in the experimental group.

Table 4: Results of ANCOVA for the mean difference of the symptoms of anxiety in the experimental group and the control group awaiting treatment

\begin{tabular}{|c|c|c|c|c|c|}
\hline Variable & Condition & $\begin{array}{l}\text { Degrees of } \\
\text { freedom }\end{array}$ & Mean squares & $\mathrm{F}$ value & $\begin{array}{l}\text { Significance } \\
\text { level }\end{array}$ \\
\hline \multirow{2}{*}{$\begin{array}{l}\text { Symptoms of } \\
\text { anxiety }\end{array}$} & Pre-test & 1 & 398.380 & 618.296 & $0.001(* *)$ \\
\hline & $\begin{array}{l}\text { Group } \\
\text { membership }\end{array}$ & 1 & 595.395 & 468.308 & $0.001(* *)$ \\
\hline
\end{tabular}

(**) The significance level was set at 0.01

As shown in Table 4, the results obtained from the univariate Analysis of Covariance (ANCOVA) indicated the effectiveness of ACT in reducing the symptoms of anxiety in veterans $(\mathrm{P}<0.001)$.

Table 5: Mean and standard deviation of pre- and post-test scores on the symptoms of depression in study groups 


\begin{tabular}{llllll}
\hline Study variables & \multicolumn{2}{l}{ Experimental } & Control & \\
\cline { 2 - 5 } & Mean & $\begin{array}{l}\text { Standard deviation } \\
(\text { SD) }\end{array}$ & Mean & $\begin{array}{l}\text { Standard deviation } \\
\text { (SD) }\end{array}$ \\
\hline $\begin{array}{l}\text { Symptoms of } \\
\text { depression (Pre-test) }\end{array}$ & 35.50 & 8.77 & 30.70 & 10.33 \\
\hline $\begin{array}{l}\text { Symptoms of } \\
\text { depression (Post-test) }\end{array}$ & 32.90 & 6.50 & 33.70 & 6.66 \\
\hline
\end{tabular}

The mean and standard deviation of the participants' scores on the BDI-II in the pre-test and posttest stages in terms of the study group are shown in Table 5. As shown in the above table, in the experimental group, the participants' mean scores on the BDI-II in both stages were 35.50 and 32.90., respectively. While the mean scores of the participants in the control group awaiting treatment in both stages were 30.70 and 33.70 , respectively. Therefore, it can be concluded that ACT reduced the symptoms of depression in the experimental group.

Table 6: Results of ANCOVA for the mean difference of the symptoms of depression in the experimental group and the control group awaiting treatment

\begin{tabular}{|c|c|c|c|c|c|}
\hline Variable & Condition & $\begin{array}{l}\text { Degrees of } \\
\text { freedom }\end{array}$ & Mean squares & F value & $\begin{array}{l}\text { Significance } \\
\text { level }\end{array}$ \\
\hline \multirow{2}{*}{$\begin{array}{l}\text { Symptoms of } \\
\text { depression }\end{array}$} & Pre-exam & 1 & 109.1095 & 702.69 & $0.001(* *)$ \\
\hline & $\begin{array}{l}\text { Group } \\
\text { membership }\end{array}$ & 1 & 437.153 & 766.9 & $0.006(* *)$ \\
\hline
\end{tabular}

(**) The significance level was set at 0.01

As shown in Table 6, the results obtained from the univariate Analysis of Covariance (ANCOVA) indicated the effectiveness of $\mathrm{ACT}$ in reducing the symptoms of depression in veterans $(\mathrm{P}<0.001)$.

Table 7: Mean and standard deviation of pre- and post-test scores on suicidal ideation in study groups

\begin{tabular}{lllll}
\hline \multirow{2}{*}{ Study variables } & \multicolumn{3}{l}{ Study groups } & Control \\
\cline { 2 - 5 } & Experimental & Mean & $\begin{array}{l}\text { Standard deviation } \\
\text { (SD) }\end{array}$ \\
\cline { 2 - 5 } & Mean & $\begin{array}{l}\text { Standard deviation } \\
\text { (SD) }\end{array}$ & 10.90 & 6.999 \\
\hline $\begin{array}{l}\text { Suicidal ideation } \\
\text { (Pre-test) }\end{array}$ & 10.80 & 8.364 & 10.60 & 6.867 \\
\hline $\begin{array}{l}\text { Suicidal ideation } \\
\text { (Post-test) }\end{array}$ & 8.40 & 6.637 & & \\
\hline
\end{tabular}

The mean and standard deviation of the participants' scores on the BSSI in the pre-test and posttest stages in terms of the study group are shown in Table 7. As shown in the above table, in the 
experimental group, the participants' mean scores on the DSSI in both stages were 10.80 and 8.40, respectively. Whereas the mean scores of the participants in the control group awaiting treatment in both stages were 10.90 and 10.60, respectively. Therefore, it can be concluded that ACT reduced suicidal ideation in the experimental group.

Table 8: Results of ANCOVA for the mean difference of suicidal ideation in the experimental group and the control group awaiting treatment

\begin{tabular}{|c|c|c|c|c|c|}
\hline Variable & Condition & $\begin{array}{ll}\text { Degrees of } \\
\text { freedom }\end{array}$ & Mean squares & $\bar{F}$ value & $\begin{array}{l}\text { Significance } \\
\text { level }\end{array}$ \\
\hline \multirow{2}{*}{$\begin{array}{l}\text { Suicidal } \\
\text { ideation }\end{array}$} & Pre-test & 1 & 786.196 & 386.236 & $0.001(* *)$ \\
\hline & $\begin{array}{l}\text { Group } \\
\text { membership }\end{array}$ & 1 & 22.350 & 10.980 & $0.004(* *)$ \\
\hline
\end{tabular}

(**) The significance level was set at 0.01

As shown in Table 8, the results obtained from the univariate Analysis of Covariance (ANCOVA) indicated the effectiveness of ACT in reducing suicidal ideation in veterans $(\mathrm{P}<0.001)$.

\section{Conclusion}

This study aimed to evaluate the effectiveness of Acceptance and Commitment Therapy (ACT) in reducing anxiety symptoms, depression symptoms, and suicidal ideation in Iranian veterans. The results obtained from this study showed that this treatment was totally effective. The results obtained from data analysis showed that ACT reduced the symptoms of depression in veterans (41, $42,43,44,45,46,47,48)$. It should be noted that emotional control strategies, performing behavioral commitment exercises, values clarification, and value-based behavior recognition techniques along with the expression of metaphors, cognitive defusion, and acceptance all reduced the symptoms of depression. This treatment aimed to help these patients accept their thoughts and feelings and be committed to the changes that occurred. These patients were also received assistance to experience their annoying thoughts only as a thought and become aware of the dysfunctional nature of the current program and instead of responding to it, move toward doing what is important and valuable to them in life. ACT teaches individuals how to Give up experiential avoidance, get rid of annoying thoughts, strengthen the observer self instead of the conceptualized self, and accept events instead of controlling them.

The results also showed that ACT reduced the symptoms of anxiety in veterans (43, 44, 46, 47, $48,49,50,51)$

This finding suggests that creative helplessness strategies, potential values, cognitive defusion, emotional control strategies, and distance from values all reduce the symptoms of anxiety. In general, avoiding experiences often increases the frequency or intensity of avoided thoughts and feelings. Trying to control anxiety requires thinking about the anxiety, which in turn brings anxiety 
to the individual; therefore, avoiding experiences strengthens them. The goal of this treatment was to help patients directly experience the ineffectiveness of the solutions they have applied so far to lose interest in and desire for them. Clients also learned to employ cognitive defusion process to doubt what they think is objectivity and create a distance between thought and feeling. Patients were able to observe the inner events as they really exist. Cognitive defusion in the ACT approach decreases the functioning of inner events as psychological barriers and thus, makes the individual exhibit less anxiety.

Moreover, the results showed that ACT reduced suicidal ideation in veterans (40, 44, 49, 50, 52, 53). This result suggests that ACT has made positive changes in some psychological functions, such as anxiety and depression and increased psychological flexibility, resulting in reduced suicidal ideation. According to clinical interviews conducted, most veterans were preoccupied with their thoughts; therefore, it attempted to demonstrate the practical meaning of defusion through utilizing the metaphors available in ACT and to make them capable of accepting their thoughts and setting aside the struggle, instead of getting caught up in their thoughts or because of those thoughts, forced to do something.

In this research, as in other studies in the humanities sciences, there are some limitations such as a small number of samples. The current study represented a small sample of veterans and may not have fully represented all veterans with depression, anxiety, and suicidal ideation; therefore, caution should be taken in generalizing the results of this research. Another limitation is being unaware of the effect of the passage of time on the reliability of therapeutic achievements due to not performing follow-up after the completion of treatment sessions. It is suggested that further research be carried out with a six-month or one-year follow-up so that, through the application of follow-up data, one can find whether the observed effects of ACT on variables will last or not.

\section{Acknowledgments}

The authors would like to express their gratitude and appreciation to veterans who participated in this research, the research officials of the Faculty of Humanities of the University of Varamin, and the esteemed director and staff of the psychiatric 505 hospital of the Islamic Republic of Iran Army Ground Forces (NEZAJA) for their assistance with performing the research and improving the quality of the research.

\section{Consent for Publication}

Not Applicable

\section{Competing Interest}

We declare no competing interests.

\section{Funding:}


Not Applicable

\section{Contributions:}

All corresponding and first authors contributed to the study concept and design.

HSH do therapy and extracted clinical data.

AMR, VD, ME, MGH analyzed the data.

AT revised it.

All authors reviewed and approved the final manuscript.

\section{Ethics declarations}

This study was approved by the Vice-Chancellor for Research and Technology of the Medical University for the Islamic Republic of Iran's Army (AJA University of Medical Sciences) (code of ethics: IR.AJAUMS.REC.1399.010). 
Refrences

1- $\quad$ Modabber R, Ebrahimi H, Kazemi A, Fallahi Khoshknab M. Relationship between suicidal ideations and psychosocial characteristics in depressed patients. Iranian Journal of Psychiatric Nursing. 2014;2(2):1-12

2- Zender R, Olshansky E. Women's mental health: depression and anxiety. Nursing Clinics. 2009;44(3):355-64

3- Wahlbeck K, Mäkinen M. Prevention of depression and suicide: Consensus paper. 2008.

4- $\quad$ Aguirre A. Suicide behavior among Latino adolescents [dissertation]. United States California: California State University, Long Beach; 2011, p.5

5- $\quad$ Thapar A, Collishaw S, Pine DS, Thapar AK. Depression in adolescence. The Lancet. 2012;379(9820):1056-67.

6- $\quad$ Mann JJ, Apter A, Bertolote J, Beautrais A, Currier D, Haas A, Hegerl U, Lonnqvist J, Malone K, Marusic A, Mehlum L. Suicide prevention strategies: a systematic review. Jama. 2005 Oct 26;294(16):2064-74.

7- $\quad$ Walser RD, Garvert DW, Karlin BE, Trockel M, Ryu DM, Taylor CB. Effectiveness of acceptance and commitment therapy in treating depression and suicidal ideation in veterans. Behaviour research and therapy. 2015;74:25-31.

8- $\quad$ Fortinash KM and Holoday Worret PA. Psychiatric Mental Health Nursing. 4thed. St. Louis: Mosby Elsevier. 2008,p.502

9- Overholser JC, Braden A, Dieter L. Understanding suicide risk: Identification of high risk groups during high times. J clin psychol. 2012; 68(3): 349-361.

10- Rahnejat AM, Dabagi P, Rabiei M, Taghva A, Valipoor H, Donyavi V, Ebrahimi MR. Prevalence of Post-Traumatic Stress Disorder Caused by War in Veterans. Ijwph. 2017;9(1):1523.

11- Dabaghi P, Cognitive behavior therapy of post-traumatic stress disorder-treatment guide for clinicians. Tehran: Jahad Daneshgahi Publication; 2008. [Persian].

12- $\quad$ Liu Y, Collins $C$, Wang K, Xie X, Bie R. The prevalence and trend of depression among veterans in the United States. Journal of affective disorders. 2019 Feb 15;245:724-7.

13- Sadeghi M, Taghva A, Goudarzi N, Rahnejat A.M. Validity and Reliability of Persian Version of "Post-Traumatic Stress Disorder Scale” in War Veterans. Iranian Journal of War \& Public Health. 2016;8(4):243-249. 
14- Curry JF, Aubuchon-Endsley N, Brancu M, Runnals JJ, Workgroup R, Workgroup VM, Fairbank JA. Lifetime major depression and comorbid disorders among current-era women veterans. Journal of affective disorders. 2014 Jan 1;152:434-40.

15- Bagalman E. The number of veterans that use VA health care services: A fact sheet. https://fas.org/sgp/crs/misc/R43579.pdf. (Accessed 22 April 2018).

16- U.S. Department of Veterans Affairs (VA), Office of Mental Health and Suicide Prevention (OMHSP). (2017). Facts About Suicide Among Women Veterans: August 2017. Available: www.mentalhealth.va.gov/docs/VA-Women-Vetera ns-Fact-Sheet.pdf. Accessed: July $18,2018$.

17- $\quad$ Arsenault-Lapierre G, Kim C, Turecki G. Psychiatric diagnoses in 3275 suicides: a metaanalysis. BMC psychiatry. 2004;4(1):37.

18- Cavanagh JT, Carson AJ, Sharpe M, Lawrie SM. Psychological autopsy studies of suicide: a systematic review. Psychological medicine. 2003;33(3):395-405.

19- Harris EC, Barraclough B. Suicide as an outcome for mental disorders. A meta-analysis. British journal of psychiatry. 1997;170(3):205-28.

20- Holma KM, Haukka J, Suominen K, Valtonen HM, Mantere O, Melartin TK, et al. Differences in incidence of suicide attempts between bipolar I and II disorders and major depressive disorder. Bipolar Disorders. 2014;16(6):652-61.

21- Nock MK, Hwang I, Sampson N, Kessler RC, Angermeyer M, Beautrais A, et al. Crossnational analysis of the associations among mental disorders and suicidal behavior: findings from the WHO World Mental Health Surveys. PLoS medicine. 2009;6(8).

22- $\quad$ Nordentoft M, Mortensen PB, Pedersen CB. Absolute risk of suicide after first hospital contact in mental disorder. Archives of general psychiatry. 2011;68(10):1058-64.

23- Kumpula MJ, Wagner HR, Dedert EA, Crowe CM, Day KT, Powell K, Batdorf WH, Shabana H, Kim E, Kimbrel NA. An evaluation of the effectiveness of evidence-based psychotherapies for depression to reduce suicidal ideation among male and female veterans. Women's Health Issues. 2019 Jun 25;29:S103-11.

24- Green BL, Grace MC, Lindy JD. Gleser GC, Leonard A.Risk factors for PTSD and other diagnoses in a general sample of Vietnam veterans. American Journal of Psychiatry 1990; 147:729-733.

25- Jordan BK, Schlenger WE, Hough RL et nl. Lifctime and current prevalence of specific psychiatric disorders among Vietnam veterans and controls. Archives of General Psychiatry $19 Y 1 ; 48: 207-21.5$. 
26- Kulka RA, Schlenger WE, Fairbank JA rr a/. Trauma and thc Vietnam War generation. New York: BrunnedMazel, 1990.

27- Chakravorty S, Grandner MA, Mavandadi S, Perlis ML, Sturgis EB, Oslin DW. Suicidal ideation in veterans misusing alcohol: relationships with insomnia symptoms and sleep duration. Addictive behaviors. 2014 Feb 1;39(2):399-405.

28- Walser RD, Garvert DW, Karlin BE, Trockel M, Ryu DM, Taylor CB. Effectiveness of Acceptance and Commitment Therapy in treating depression and suicidal ideation in Veterans. Behaviour research and therapy. 2015 Nov 1;74:25-31.

29- Hayes L, Boyd CP, Sewell J. Acceptance and commitment therapy for the treatment of adolescent depression: A pilot study in a psychiatric outpatient setting. Mindfulness. $2011 \mathrm{Jun}$ $1 ; 2(2): 86-94$

30- Kashdan TB, Rottenberg J. Psychological flexibility as a fundamental aspect of health. Clinical psychology review. 2010 Nov 1;30(7):865-78..

31- Hayes SC, Luoma JB, Bond FW, Masuda A, Lillis J. Acceptance and commitment therapy: Model, processes and outcomes. Behaviour research and therapy. 2006 Jan 1;44(1):1 25.

32- McCracken LM, Sato A, Taylor GJ. A trial of a brief group-based form of acceptance and commitment therapy (ACT) for chronic pain in general practice: pilot outcome and process results. The journal of pain : official journal of the American Pain Society. 2013;14(11):13981406.

33- Walser RD, Karlin BE, Trockel M, Mazina B, Barr Taylor C. Training in and implementation of acceptance and commitment therapy for depression in the veterans health administration: therapist and patient outcomes. Behaviour research and therapy. 2013;51(9):555-563.

34- Walser RD, Karlin BE, Trockel M, Mazina B, Taylor CB. Training in and implementation of Acceptance and Commitment Therapy for depression in the Veterans Health Administration: Therapist and patient outcomes. Behaviour Research and Therapy. 2013;51(9):555-63.

35- Beck AT, Epstein N, Brown G, Steer RA. An inventory for measuring clinical anxiety: psychometric properties. Journal of consulting and clinical psychology. 1988 Dec;56(6):893.

36- Fathi-e-Ashtiani A, Dastani M. Psychological Tests: Personality and Mental Health. Tehran: Be'sat. Persian; 2009.

37- Beck AT, Steer RA, Brown GK. Bdi-ii manual. 1996. 
38- Beck AT, Ward C, Mendelson M, Mock J, Erbaugh J. Beck depression inventory (BDI). Arch Gen Psychiatry. 1961;4(6):561-71.

39- Beck AT, Steer RA. Beck scale for suicide ideation: Psychological Corporation; 1991.

40- Walser RD, Garvert DW, Karlin BE, Trockel M, Ryu DM, Taylor CB. Effectiveness of acceptance and commitment therapy in treating depression and suicidal ideation in veterans. Behaviour research and therapy. 2015;74:25-31.

41- Walser R, Sears K, Chartier M, Karlin B. Acceptance and commitment therapy for depression in veterans: Therapist manual. Washington, DC: US Department of Veterans Affairs. 2012.

42- $\quad$ Szanto K, Mulsant BH, Houck P, Dew MA, Reynolds CF. Occurrence and course of suicidality during short-term treatment of late-life depression. Archives of general psychiatry. 2003;60(6):610-7.

43- Karlin BE, Walser RD, Yesavage J, Zhang A, Trockel M, Taylor CB. Effectiveness of acceptance and commitment therapy for depression: Comparison among older and younger veterans. Aging \& mental health. 2013;17(5):555-63.

44- $\quad$ Yadavaia JE, Hayes SC, Vilardaga R. Using acceptance and commitment therapy to increase self-compassion: A randomized controlled trial. Journal of contextual behavioral science. 2014;3(4):248-57.

45- $\quad$ Twohig MP. Acceptance and commitment therapy for treatment-resistant posttraumatic stress disorder: A case study. Cognitive and Behavioral Practice. 2009;16(3):243-52.

46- Woidneck MR, Morrison KL, Twohig MP. Acceptance and commitment therapy for the treatment of posttraumatic stress among adolescents. Behavior Modification. 2014;38(4):45176.

47- $\quad$ Sharp K. A review of acceptance and commitment therapy with anxiety disorders. International Journal of Psychology and Psychological Therapy. 2012;12(3):359-72.

48- $\quad$ Orsillo SM, Batten SV. Acceptance and commitment therapy in the treatment of posttraumatic stress disorder. Behavior modification. 2005;29(1):95-129.

49- Kearney DJ, McDermott K, Malte C, Martinez M, Simpson TL. Association of participation in a mindfulness program with measures of PTSD, depression and quality of life in a veteran sample. Journal of clinical psychology. 2012;68(1):101-16.

50- Ducasse D, René E, Béziat S, Guillaume S, Courtet P, Olié E. Acceptance and commitment therapy for management of suicidal patients: a pilot study. Psychotherapy and psychosomatics. 2014;83(6):374. 
51- Bluett EJ, Homan KJ, Morrison KL, Levin ME, Twohig MP. Acceptance and commitment therapy for anxiety and OCD spectrum disorders: An empirical review. Journal of anxiety disorders. 2014;28(6):612-24.

52- $\quad$ Folke F, Parling T, Melin L. Acceptance and commitment therapy for depression: A preliminary randomized clinical trial for unemployed on long-term sick leave. Cognitive and behavioral practice. 2012;19(4):583-594.

53- Hayes SC, Strosahl KD, Wilson KG. Acceptance and commitment therapy: An experiential approach to behavior change. New York: Guilford Press; 1999. 
Table 2: How to implement the ACT protocol

\begin{tabular}{|c|c|c|}
\hline sessions & topic & content \\
\hline Session 1 & $\begin{array}{l}\text { Informed } \\
\text { Consent; Formal } \\
\text { and Informal } \\
\text { Assessment; } \\
\text { Rapport Building }\end{array}$ & $\begin{array}{l}\text { Therapist preparation, self-report, Provide the rationale for } \\
\text { mindfulness (definition of mindfulness, Discussion of the } \\
\text { exercise), consent, commitment to therapy and course of } \\
\text { treatment, Conduct formal and informal assessments } \\
\text { including a suicide risk assessment, Alliance building, } \\
\text { Assign homework/behavioral commitments }\end{array}$ \\
\hline Session 2 & $\begin{array}{l}\text { Values } \\
\text { Assessment/Goals } \\
\text { of Therapy }\end{array}$ & $\begin{array}{l}\text { Therapist preparation, self-report, Select and prepare } \\
\text { mindfulness exercise (Body Scan), Review prior session } \\
\text { and homework, values assessment (What do I want my life } \\
\text { to stand for?), Assign homework/behavioral commitments. }\end{array}$ \\
\hline Session 3 & $\begin{array}{l}\text { Creative } \\
\text { Hopelessness }\end{array}$ & $\begin{array}{l}\text { Therapist preparation, self-report, Select and prepare } \\
\text { mindfulness exercise (Mindful seeing followed by mindful } \\
\text { stretching), Review prior session and homework, creative } \\
\text { hopelessness (Man-in-the-hole metaphor, ...), Assign } \\
\text { homework/behavioral commitments }\end{array}$ \\
\hline Session 4 & $\begin{array}{l}\text { Control as the } \\
\text { Problem }\end{array}$ & $\begin{array}{l}\text { Therapist preparation, self-report, Select and prepare } \\
\text { mindfulness exercise (Mindfulness of the breath, sound, } \\
\text { and thoughts), Review prior session and homework, control } \\
\text { as the problem (Driving with the rear-view mirror } \\
\text { metaphor, ...), Assign homework/behavioral commitments }\end{array}$ \\
\hline Session 5 & $\begin{array}{l}\text { Willingness: } \\
\text { Building } \\
\text { Acceptance, } \\
\text { Defusing } \\
\text { Language - Part I }\end{array}$ & $\begin{array}{l}\text { Therapist preparation, self-report, Select and prepare } \\
\text { mindfulness exercise (Acceptance of feelings exercise), } \\
\text { Review prior session and homework, willingness: building } \\
\text { acceptance, defusing language - part I(Cognitive } \\
\text { Defusion/Distancing Techniques), Assign } \\
\text { homework/behavioral commitments }\end{array}$ \\
\hline Session 6 & $\begin{array}{l}\text { Willingness: } \\
\text { Building } \\
\text { Acceptance, } \\
\text { Defusing } \\
\text { Language - Part } \\
\text { II }\end{array}$ & $\begin{array}{l}\text { Therapist preparation, self-report, Select and prepare } \\
\text { mindfulness exercise (Acceptance of thoughts), Review } \\
\text { prior session and homework, willingness: building } \\
\text { acceptance, defusing language - part II(Distancing From } \\
\text { Thoughts), Assign homework/behavioral commitments }\end{array}$ \\
\hline
\end{tabular}




\begin{tabular}{|c|c|c|}
\hline Session 7 & $\begin{array}{l}\text { Self-as-Context - } \\
\text { Part I }\end{array}$ & $\begin{array}{l}\text { Therapist preparation, self-report, Select and prepare } \\
\text { mindfulness exercise (Acceptance of Anxiety), Review } \\
\text { prior session and homework, willingness: building } \\
\text { acceptance, self-as-context - part I (Acceptance of anxiety } \\
\text { exercise), Assign homework/behavioral commitments }\end{array}$ \\
\hline Session 8 & $\begin{array}{l}\text { Self-as-Context - } \\
\text { Part II }\end{array}$ & $\begin{array}{l}\text { Therapist preparation, self-report, Select and prepare } \\
\text { mindfulness exercise (Acceptance of depression and } \\
\text { suicidal ideation), Review prior session and homework, } \\
\text { willingness: building acceptance, self-as-context - part II } \\
\text { ((Acceptance of depression exercise), Assign } \\
\text { homework/behavioral commitments }\end{array}$ \\
\hline Session 9 & Values - Part I & $\begin{array}{l}\text { Therapist preparation, self-report, Select and prepare } \\
\text { mindfulness exercise (Compassion Exercise), Review prior } \\
\text { session and homework, willingness: building acceptance, } \\
\text { values - part I (What would it say on your tombstone? } \\
\text { Exercise,...), Assign homework/behavioral commitments }\end{array}$ \\
\hline Session 10 & Values - Part II & $\begin{array}{l}\text { Therapist preparation, self-report, Select and prepare } \\
\text { mindfulness exercise (Word/Phrase Exercise), Review prior } \\
\text { session and homework, willingness: building acceptance, } \\
\text { values - part II (Choice and moment by moment choosing } \\
\text { exercise,...), Assign homework/behavioral commitments }\end{array}$ \\
\hline Session 11 & $\begin{array}{l}\text { Committed } \\
\text { Action }\end{array}$ & $\begin{array}{l}\text { Therapist preparation, self-report, Select and prepare } \\
\text { mindfulness exercise (Yes and No Exercise), Review prior } \\
\text { session and homework, willingness: building acceptance } \\
\text { (ACT: Accept, Choose, Take action Technique,...), } \\
\text { committed action, Assign homework/behavioral } \\
\text { commitments }\end{array}$ \\
\hline Session 12 & Termination & $\begin{array}{l}\text { Therapist preparation: review concepts and session } \\
\text { materials, Select and prepare mindfulness exercise (Mindful } \\
\text { Walking), Review prior session and homework, } \\
\text { termination, Wrap up, Stand and commit, Suggested post- } \\
\text { treatment assessments }\end{array}$ \\
\hline
\end{tabular}

